\title{
Integrating Self-Reliance Education Curriculum For Purdah Women In Northern Nigeria: A Panacea For A Lasting Culture Of Peace
}

\author{
Asst. Lecturer: Aisha Isa, Dem, B.Ed, M.Ed (Buk) \\ Science Education Department, University Of Science And Technology, Wudil, Kano, Nigeria.
}

\begin{abstract}
Illiteracy and poverty are predicament which put women at high risk of exploitation and violation of rights. Yet, women are expected to grow into the good mother of tomorrow even in the face of these disadvantages. women are integral part of national development, hence, efforts should be geared towards their empowerment. If this is achieved, it can have positive effect on the socio-cultural peaceful co existence in Nothern Nigeria. This paper advocates for Purdahrian Self-Reliance(PSR) education curriculum for women, to secure lasting culture of peace through: proliferation of women centers and adult literacy classes.
\end{abstract}

Keywords: self-reliance,Women, peace, Nigeria.

\section{Introduction}

Education at all levels is the process through which individuals are made functional members of their society. It is also a process, through which the individual acquires knowledge, realizes his/her potentialities, and uses them for self actualization and to be useful to others. For the woman however, she may not be so lucky to be that protected due to illiteracy, certain traditional beliefs, and poverty which may put her at high risk of abuse, neglect exploitation and violation of her right. Illiteracy and poverty are factors which put the woman at high risk of exploitation and violation of her right. Yet, she is expected to be a good mother even in the face of these disadvantages. Indeed, Although, there is a policy on women Education in Northern Nigeria and accross the Globe, it is in Place rather than in practice. Therefore, it is significant to Integrate Self-reliance Education Curriculum for Purdah women in Northern Nigeria.

\section{The Concept Of Self-Reliance}

Self-reliance is one of the bases of effective community development in Africa. In fact, the concept of self-reliance is located centrally within the discourse of community development and is connected to related concepts like self-help, mutual-help, indigenous participation and rural development. Isa (2014) advocates that "Self-reliance is the need for people to unfold and realise their creative potentials which will enable them to improve their material condition of living using local initiatives and resources available to them".

Anyanwu (1992) contends that in most African countries community development has depended significantly on voluntary cooperative effort. This explains the emerging trend in community development, which sees it as an important point of take-off for better living. The emphasis is to involve groups of people in planned programmes from which they may gain skills that will enable them to cope more successfully with the problems of their everyday life. Self-reliance is thus "development on the basis of a country's (region's) own resources, involving its populations based on the potentials of its cultural values and traditions"(Galtung 1980). Communities and individual people define their own development according to their own needs, values and aspirations (Preiswerk, 1980). It is againstthis back drop that, the researcher saw the need to to over view womens Education accross the Globe, so as to pave way to develop and implement the Purdahrian SelfReliance Education Curriculum which is meant to assist women folk globally.

\section{Women's Education Display in Northern Nigeria and Accross the Globe}

In 1986, the Blueprint on Women Education in Nigeria was launched, followed by the setting up of "Women Education Units" in Federal and State Ministries of Education. These units cater for both rural and urban women, drop-outs at secondary schools, as well as literate women who desire to further their education. Attention was also focused on women with special needs such as nomadic and women in purdah, drop-outs of all categories, especially teenage single parents. The overall aim is to avail all women of equal educational opportunities, irrespective of their age, locality, creed or social status. Apart from conducting adult literacy classes, the "Women Education Units" also run women's vocation centres in all Local Government Areas in Northern Nigeria. Many crafts and skills are imparted, reflecting both traditional occupations of a particular locality as well as modern-day pursuits. Thus, apart from skills and crafts such as cloth weaving. "tie and die", farming, food processing and preservation, the centres also run courses on dress-making, hair dressing soap- 
making, cookery cosmetology, secretarial and computer studies, etc. In some cases, extra-mural classes were also offered to beneficiaries, especially the younger ones, the opportunity to gain qualifications that will enable them to mainstream in formal educational institutions. To this end, certification is usually awarded on the successful completion of such courses, while the "Women Education Units" collaborate with formal sector institutions such as Technical Colleges, Polytechnics and Colleges of education to integrate suitable and desirous graduates of the Adult and Non-formal Education courses into the formal education system.

In some years back, the Family Support Progromme (FSP) and the Federal and State Ministries of Women's Affairs have also embarked on many adult and non-formal educational programmes for girls and women in Northern Nigeria.

\section{contributions of NGOs andDonor Agencies to Women Education in Nigeria.}

Many Christian and Muslim women's organisations are active in offering adult and non-formal education opportunities to women; so also are many other NGOs such as Officers Wives Associations, Associations of the Nigerian Armed Forces (Amy, Navy and Air Force). Donor agencies such as UNICEF, UNESCO, UNDP, British Council. Van Leer Education Foundation, etc all contribute enormously to various educational programmes for women. For example, in the UNICEF/FGN Master Plan of Operations for the 1991 - 1995 Programme of Cooperation. The education of women is identified as one of the areas of UNICEF's intervention in Nigeria and accross the globe.

\section{Purdahrian Curricullum Advocatism on Self-Reliance Education for Women The Concept of Purdah}

The meaning of Purdah varies from society to society. In some perspective,

Purdah is viewed as a screen or curtain, shield or barrier (Encarta Dictionary). Purdah is used in some Hindu communities to

keep women out of view. Some times, it could be referred to as a veil worn

by some Hindu and Muslim women as a shield or barrier (from sexual harrassment,molestation anarchy and degredation).

Consequently, the concept of purdah is and far beyond this context viewed by different persons and communities. Isa (2014) contends that "Purdah is a protective (shield) to human and material resources on earth. The protective is usually sealed, such that no external force can penetrate into it, to either alter or destroy the origin". She added, the purdah is used as a protective for the care of the planet earth and the planet earth is in a Globe form surrounded by human and material resources. If the resources sorrounding the Globe are judiciously utilized, the planet earth remains peaceful and progressive. On the other hand, if the resources (human and material) are under utilized, all that is contained within and outside the Globe will regress. Here, the idea of presenting the PSR curriculum advocatism in a global form is based on the fact that, Purdahrian is flexible and each progressive stage inter-relates to the next progressive stage continously without a terminal point. Moreso, at the original stage, any defective detected and attended to (tackled) becomes regressive. But, any defective detected and neglected becomes destructive. This is represented below:-

Defective $\Rightarrow$ Detected $\Rightarrow$ Attended $\Rightarrow$ Defective(Regressive)

\section{Defective $\Rightarrow$ Detected $\Rightarrow$ Neglected $\Rightarrow$ Destructive(Progressive).}

Characteristics of Pudahrian Self-Reliance Curriculum

The PSR curriculum consist of four stages with protective in each progressive stage, leading to the next progressive stage namely:-

$>$ Origin
$>$ Communication
$>$ Organization
$>$ Implementation

$>\quad$ Origin: origin means the actual phenomena. It includes the intention to be spelt out. It deals with four basic questions.

1. What do we intend to acheive?

2. How do we intend to acheive?

3. Why do we intend to acheive?

4. Who are the target audience?

This stage can be applied to the industrial sector for example in this stage, Northern Nigeria could aim at the "proliferation of milk industry for global consumption

$>\quad$ Communication (content): This refers to the channel of interaction between the learners and the facilitators in order to appreciate the knowledge and skills of the origin in a protective manner for a desirable 
outcomes; this includes - Language of communication (Hausa/Fulfulde). Traditional values (acceptable traditional dress code). Basic knowledge and Skills- this include subject description e.g diet \& nutrition for females and Agricultural science for males, Civic Education, Hygiene, Religious Knowledge, Mathematics and English Language at a later stage. Origin Policy- The origin policy is a guide for protective implementation it clearly spelt out the intention, activities, methodology and evaluation of the entire program to be achieved.

Organization: This refers to the procedure and the structural adjustment to be in place in a protective manner to achieve the aspirations of the origin for a desirable outcome. This include the venue e.g where the milk industry will be cited ( for practical) with adult literacy classes and women centres within the industrial premises. Time tabling and funding of the project will be deliberated at this stage.

Implementation: Here, implementation refers to the delivery stage and the protective bodies that will assist in the delivery process e.g volunteers and indigeneous members are hereby required to make sure that the origin is protected, they include facilitators, agriculturists, health educators, religist, media industry, individuals and community groups, NGO's and philantrophic contributions in terms of land, labour, capital and intreprenuership. However, Purdah has been considered as a protective guard to human and material resources on Earth with the planet Earth represented in a global shape, surrounded by human and material resources. If utilized, the planet remains peaceful and habitable. If otherwise both the human and material resources in it will suffer. The purdahrian advocatism has its origin from the ground level which means the root (source/origin) if the root is protected the entire circle is protected and if any defect is detected in any progressive stage and itis tackled, the defect becomes regressive. But if the defect detected is neglected and untakled the defect becomes destructive to the entire progressive stages around the Globe. This fact is represented in the diagram below:

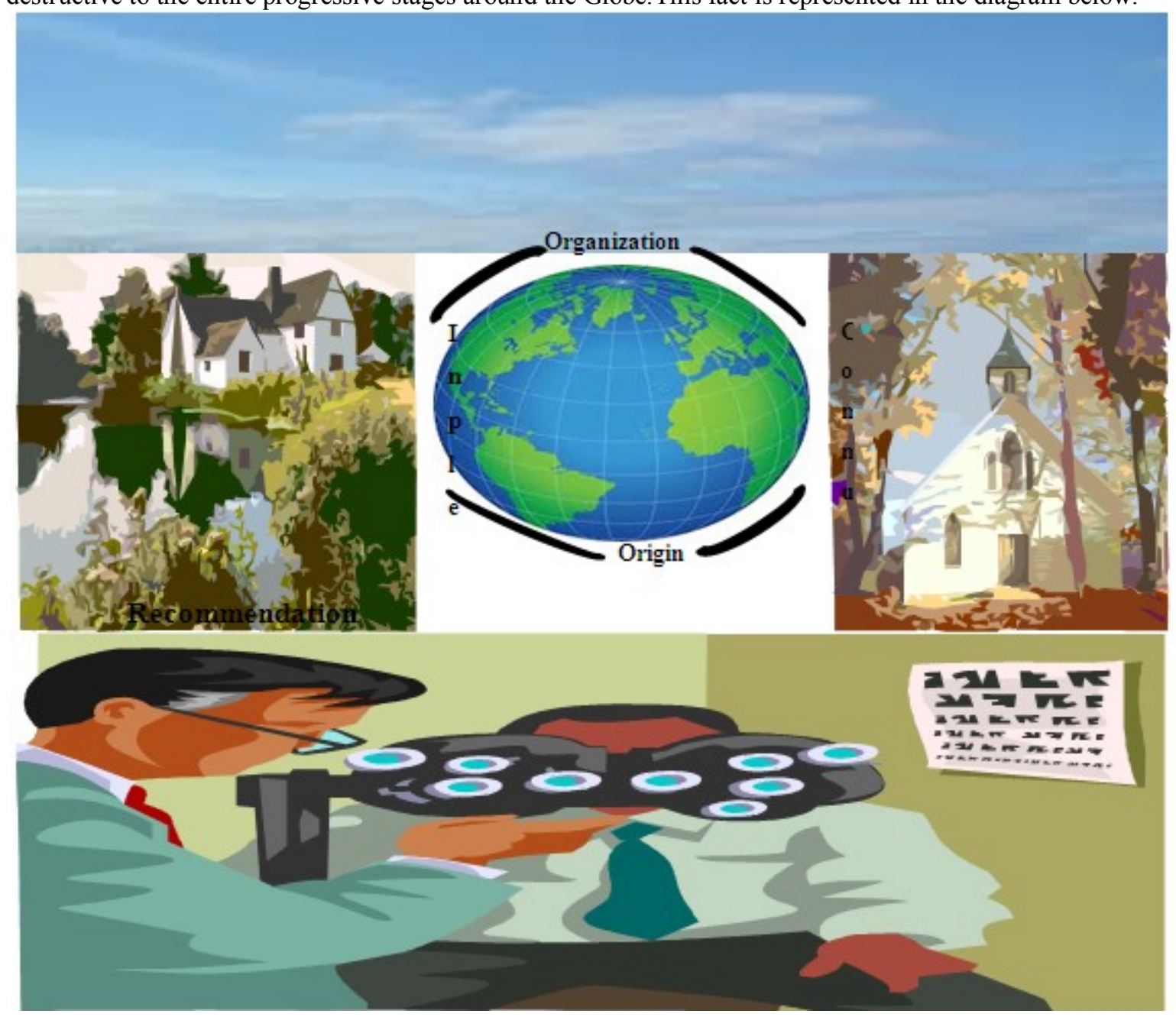

III. Recommendation

The Purdahrian Self -Reliance Education Curriculum according to the result of the study was rich and adequate enough with experiences that will facilitate learning. However, the following suggestions will go a long way in the improvement of the curriculum interms of implementation:

a. The curriculum needs to be reviewed constantly.

b. Women /Adult Education facilitators should be provided with opportunities to go for in-service training. 
c. There should be improvement on supervision and inspection of Women Education Centres.

d. Women/Adult education Centres should be provided with adequate instructional facilities.

e. Evaluation of Adult Education programme should be done as and when due.

f. Women/Adult learners should be financed to go on field trips.

g. Condusive classroom atmosphere should be provided to facilitate learning and it should be cited near or within the industry.

h. The Women Education facilitators should be restricted to only those who specialized in the area.

i. The PSR curriculum should reflect the needs of the women and the immediate environment.

j. Curriculum innovation in Women/Adult Education centres should be made in line with the modern world of Technology.

k. Adequate time should be allocated to practical courses.

1. The community and Non-governmental organizations should contribute efficiently and effectively, in the proliferation and development of Women Centres and Adult literacy classes.

\section{Conclusion}

The PSR curriculum advocatism, can be applied in various facette of human endeavour in order to achieve an intended goal. This theory can be applied in the Health sector, where as it can be used to conduct a laboratory test to be able to diagnose, prescribe and treat (cure) human diseases. Just as it can be used medically to treat the disease of the heart to cure ailment, it can also be used religiously to sanitize the heart from corruption, injustice, anarchy etc. In other words, it can be judiciously utilised to pave way for Sustaining Peace on the lanet Earth. Similarly, while the PSR curriculum advocatism can be used to achieve the mission of a country for a global benefit, this theory could be applicable in all human facette of development namely political, agricultural \& economic spheres. Like in the industrial sector, for many years ago, in San Diego California, USA. The Tuna industry was set up to provide sea food globally. This culminated to executing a workable blue print in a protective manner and the result of what is intended is achieved today. Similarly, at a time, the Tanzanian in Africa intends to produce average literate citizens which results to initiating the "each one teach one" and today the Tanzanians have achieved their intension towards promoting literacy Nationally and even globally as some other developing countrie, are advocating and working hard to replicate the Tanzanian literacy achievement in their own countries.Indeed, Nigeria the biggest of Africa is one of the such countries To this end, Nigeria and Nothern Nigeria in particular, can use the PSR curriculum advocatism to "proliferate the milk industry for global consumption". If the PRS is adopted, the under utilization of the cow milk by the Northern women who usually sell the milk in form of local yoghurt and some times unhygienically prepared and packaged with devalued nutritional content, will gain prosperity in such a way that self-reliance education opportunity will be offered to the Northern women in purdah to promote milk industry globally. This idea can be embraced among the normad in Chad, Cameroon, Philipines and the Arab world. Using the PSR to achieve this intension, all stake holders must put hands on deck to contribute towards the realization of a vibrant economy fostered by the Nigerian citizens, ranging from facilitators, volunteers, Agriculturist, food scientist, Health Educators, the media and both philanthropic as well as the non -philanthropic organizations, must all play a vital role in a protective manner, to ensure the successful implementation of the "origin" (intension) in order to bring about a radical and a new dimensioned, Self -reliant community, in Northern Nigeria which can be imitated nationally and globally, to take good care of all progressive sphere's in the planet earth with a view to sustain and maintain peace globally.However, the adoption of the purdahrian advocatism will compliment the government effort both local central and federal to secure more employment oppurtunities not only as it was cited in Northern Nigeria, but also in various communities and in diverse economic sphere across the globe. By encouraging self reliance, peace is promoted globally.

\section{References}

[1]. A. Ahmad, (2003): "Gender Education in Nigeria: implication for Curriculum Implementation". Kano Journal of Education Studies.

[2]. K AJEST VOL. 2 NO: 1, The Journal of the Department of Education, Bayero University Kano, pp. 81-84.

[3]. A. Rufai, (3003): “'Gender Education in Nigeria: implication for Curriculum Implementation”. Kano Journal of Education Studies.

[4]. JEST VOL. 2 NO: 1, The Journal of the Department of Education, Bayero University Kano, pp. 81-84.

[5]. F.G. Dantata, (2005): “Accelaration of the Girl-child education in northern nigeria".Kano Journal of Education Studies. KAJEST

[6]. VOL. 2 NO: 1, The Journal of the Department of Education, Bayero University Kano, pp. 81-84.

[7]. Okafor, E.C. (2011) The role of Vocational and Technical Education in Manpower Development and Job creation in Nigeria. Awka, Nigeria:

[8]. The Constitution of the Federal Republic of Nigeria 1999, p. 13.

[9]. The New Webster's Dictionary of English Language (International Edition). New York, USA: Lexicon Int. Publishers Group.

[10]. Wasagu, M.A. \& Mohammed, R. (2009, 23rd August) Development Enterpreneurial Skills through Science, Technology and Mathematics (STM) Education: A Path to Empowerment of the Nigeria Women. Paper presented at the 50th Conference of Science Teachers Association of Nigeria (STAN) at Minna, Niger State. 